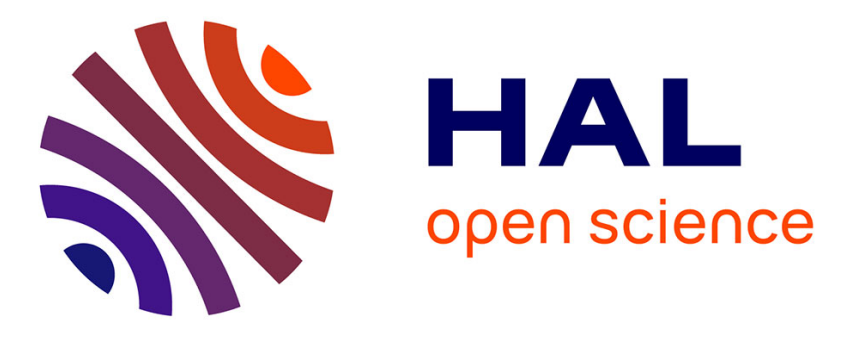

\title{
Dynamic modeling of ships towed by kite
}

Nedeleg Bigi, Morgan Behrel, Kostia Roncin, Jean-Baptiste Leroux, Alain Nême, Christian Jochum, Yves Parlier

\section{To cite this version:}

Nedeleg Bigi, Morgan Behrel, Kostia Roncin, Jean-Baptiste Leroux, Alain Nême, et al.. Dynamic modeling of ships towed by kite. La Houille Blanche - Revue internationale de l'eau, 2018, 2018 (1), pp.8-10. 10.1051/lhb/2018002 . hal-01784376

\section{HAL Id: hal-01784376 \\ https://hal-ensta-bretagne.archives-ouvertes.fr/hal-01784376}

Submitted on 18 Oct 2021

HAL is a multi-disciplinary open access archive for the deposit and dissemination of scientific research documents, whether they are published or not. The documents may come from teaching and research institutions in France or abroad, or from public or private research centers.
L'archive ouverte pluridisciplinaire HAL, est destinée au dépôt et à la diffusion de documents scientifiques de niveau recherche, publiés ou non, émanant des établissements d'enseignement et de recherche français ou étrangers, des laboratoires publics ou privés. 


\title{
Dynamic modeling of ships towed by kite
}

\author{
Nedeleg BIGI ${ }^{1}$, Morgann BEHREL ${ }^{1}$, Kostia RONCIN ${ }^{1}$, Jean-Baptiste LEROUX ${ }^{1}$ \\ Alain NEME ${ }^{1}$, Christian JOCHUM ${ }^{1}$, Yves PARLIER ${ }^{2}$
}

\author{
' ENSTA Bretagne, FRE CNRS 3744, IRDL, F-29200 Brest, France, nedeleg.bigi@ensta-bretagne.org \\ ${ }^{2}$ beyond the sea, 1010 avenue de l'Europe, 33260 La Teste de Buch, France, yves.parlier@beyond-the-sea.com
}

\begin{abstract}
A dynamic kite flight can affect ship motions. Ship equations of motion associated with the analytical zero-mass kite model are developed. Aiming a realistic amplitude modeling of the kite excitation, a linear modification of the aerodynamic kite specs with the turning rate of the kite velocity heading is proposed. A good agreement with experimental data is obtained. Equations of motion are solved on a reaching path alternatively with a weak and a strong coupling between the ship and the kite. Differences between the two coupling methods become significant when a harmonic of the kite excitation approaches the natural roll frequency of the ship. For the presented case of study, these critical conditions can be avoided with longer tethers or larger kite trajectories.
\end{abstract}

Keywords: kite, ship, dynamic simulation, time domain simulation, seakeeping, roll, frequency analysis, strong coupling, weak coupling

\section{Modélisation dynamique des navires tractés par cerf-volant}

\begin{abstract}
RÉSUMÉ. - La traction des navires par cerf-volant permet d'économiser du carburant. Cependant, le vol dynamique de cerf-volant peut modifier les mouvements d'un navire. Ainsi les équations du mouvement avec un modèle cinématique de cerf-volant sont développées. Afin de correctement modéliser l'amplitude d'excitation du kite, une évolution linéaire du coefficient de portance et de l'angle de finesse en fonction de la dérivée temporelle de la direction de la vitesse du kite est proposée et donne de bons résultats par rapport à l'expérience. Par la suite, les équations du mouvement sont résolues avec un couplage fort et un couplage faible entre le kite et le navire. Les écarts entre les deux couplages sont importants quand les harmoniques d'excitation coïncident avec la fréquence propre de roulis du navire. Ces conditions sont à éviter car le navire est alors animé de mouvements de grandes amplitudes. Pour le cas d'étude présenté, ces conditions critiques peuvent être évitées avec des grandes longueurs de lignes ou des grandes trajectoires de cerf-volant.
\end{abstract}

Mots-clés : cerf-volant, navire, simulation dynamique, simulation temporelle, tenue à la mer, roulis, analyse fréquentielle, couplage fort, couplage faible

\section{INTRODUCTION}

This work takes place within the beyond the sea ${ }^{\circledR}$ research program which aims to develop kites as an auxiliary propulsion device of ships for fuel saving. Dynamic simulations of a ship towed by kite were performed by Bigi et al. [2017]. They showed that such a system is significantly coupled near the natural roll frequency of the ship. A strong coupling is performed into the time domain with a ship model based on the impulse response function [Cummins, 1962], the STF strip theory [Salvesen et al., 1970] and a zero-mass kite model [Leloup et al., 2016]. Thanks to the use of a state space model to compute the convolution product [Fossen, 2005], the time domain method is faster than the real time one on a desktop computer. Equations of motion of the system are presented in section II. Moreover, Behrel et al. [2017] showed that the steering of the tethers to control the kite leads to significant modifications of the kite aerodynamic coefficients due to important changes in the flying shape of the kite. Consequently, the amplitude of the kite excitation is underestimated by the zero-mass model where a constant lift to drag angle and a constant lift coefficient were considered. Therefore, a modification for the kite aerodynamic coefficients is proposed in section III. In section IV, a comparison of the strongly coupled model presented with the corresponding weakly coupled system is performed for different tether lengths leading to different excitation spectra and results are presented and discussed.

\section{EQUATIONS OF MOTION OF A SHIP TOWED BY KITE}

The considered system of equations of motion for a ship towed by kite is given by Eq. (1). The first four equations of the system denote the ship equations of motion. This set of equations is similar to the equations of motion proposed by Fossen [2005]. The first equation represents the transformation of $\underline{V}_{s}$ into the earth fixed frame, the generalized ship velocity (linear velocity and turning rate) expressed into the ship fixed frame at $O_{s}$, (cf. Fig. 1).

Applying the Newton's law, the generalized ship acceleration vector expressed into the ship fixed frame is presented in the second equation. $A$ and $B$ are respectively the frequency dependent added $\overline{\bar{m}}$ ass an $\overline{\bar{d}}$ damping matrix.

denotes the limit towards infinite frequency. $D$ and $C$ are respectively the centripetal and restoring matrix. The third and the fourth equations are the state space systems, $\left\{\underline{A}_{i j}^{\prime}, \underline{B}_{i j}^{\prime}, \underline{C}_{i j}^{\prime}\right\}$, modeling the convolution product, $\int_{-\infty}^{t} \underline{H}(t-\tau) \delta \underline{V}_{s}(\tau) d \tau$, where $\underline{\underline{H}}$ denotes the retardation matrix. 


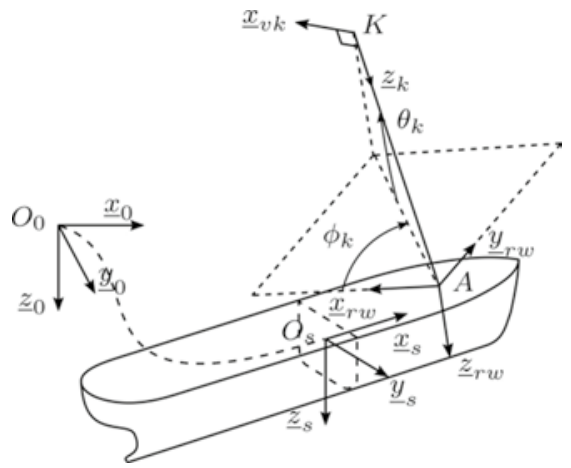

Figure 1: Coordinate system and parameterization

The Laplace transform of $\underline{H}$ can be expressed as $\underline{\underline{H}}(j \omega)=\underline{\underline{B}}(\omega)-\underline{\underline{\tilde{B}}}+j \omega[\underline{\underline{A}}(\omega)-\tilde{\tilde{\tilde{A}}}]$ and is obtained according to the STF strip theory (Salvesen et al., 1970). To speed up the simulation the convolution product is computed with state space systems, see [Perez and Fossen, 2008].

The novelty of this study lays in the last equation which expresses the kite velocity according to the zero-mass model with respect to the earth reference frame. $\underline{U}_{k}$ is the kite velocity with respect to the tether attachment point A on the ship. $\underline{U}_{a}$ denotes the velocity of A. Both masses of tether and kite are neglected. The tether is assumed to be straight with a constant length $L_{t}$. Consequently, for any configuration the tether tension is directly opposed to the aerodynamic kite force. Assuming that the apparent wind velocity stays in the symmetry plane of the kite, Leloup et al. [2016] expressed the kite velocity, with respect to the tether attachment point, as follows:

$\underline{U}_{k}=U_{r w}\left[\underline{x}_{v k} \cdot \underline{x}_{r w}+\sqrt{\left(\underline{x}_{v k} \cdot \underline{x}_{r w}\right)^{2}+\left(\underline{z}_{k} \cdot \underline{x}_{r w} / \sin \varepsilon_{k}\right)^{2}-1}\right] \underline{x}_{v k}$

where $\underline{U}_{r w}$ and $\underline{x}_{r w}$ are respectively the relative wind speed magnitude and direction, $\varepsilon_{k}$ denotes the lift to drag angle. $\underline{z}_{k}$ is defined by $\underline{A K} /\|\underline{A K}\|$, where $K$ stands for kite position. $\underline{x}_{v k}$ is the kite velocity direction and $\underline{x}_{v k} \cdot \underline{z}_{k}$. The relative wind speed is given by the velocity difference of the true wind speed and the tether attachment point velocity on the ship as follows: $\underline{U}_{r w}=\underline{U}_{t w}-\underline{U}_{a}$, leading to a relative wind speed which is not necessarily horizontal. The kite velocity direction $\underline{x}_{v k}$ is controlled in order to follow a given trajectory. According to Leloup et al. [2016], the tether tension is given by the following formula: $\underline{T}_{k}=-\rho_{a} C_{l k} A_{k} U_{a w}^{2} \underline{z}_{k} /\left(2 \cos \varepsilon_{k}\right)$ where, $\rho_{a}, C_{l k}$ and $A_{k}$ denote respectively the air density, the kite lift to drag angle and the kite area. The apparent wind speed is expressed as follows: $\underline{U}_{a w}=\underline{U}_{r w}-\underline{U}_{k}$. The generalized kite towing force expressed at $O_{s}$ is given by $\underline{F}_{k}=\left[\begin{array}{ll}\underline{T}_{k} & \underline{O_{s}} A \times \underline{T}_{k}\end{array}\right]^{T}$.

$$
\left\{\begin{array}{l}
\underline{\dot{X}}_{s}=\left[\begin{array}{ll}
\underline{T} & \underline{0} \\
\underline{0} & \underline{R}
\end{array}\right] \underline{\dot{V}}_{s} \\
\underline{\dot{V}}_{s}=[\underline{\underline{M}}+\tilde{A}]^{-1}\left[\underline{F}_{k}-\left(\underline{\underline{\tilde{B}}}+\underline{\underline{D})} \underline{\underline{V}}_{s}-\underline{\mu}-\underline{\underline{C}} \underline{\underline{S}}\right]\right. \\
\underline{\underline{y}}_{i j}=\underline{A}_{i j}^{\prime} \underline{y}_{i j}+\underline{B}_{i j}^{\prime} V_{s, j}, \quad \forall i, j \in\{1, \ldots, 6\} \\
\mu_{i j}=\sum_{j=1}^{6} \underline{B}_{i j}^{\prime} \underline{y}_{i j}, \quad \forall i, j \in\{1, \ldots, 6\} \\
\underline{\dot{K}}=\underline{U}_{k}+\underline{U}_{a}
\end{array}\right.
$$

Note that the strongly coupled system takes into account the instantaneous tether attachment point velocity $\underline{U}_{a}$, whereas the weakly coupled system solves ship motions assuming that the ship velocity is constant over the computation of the kite motion.

\section{3 COMMENTS ON KITE AERODYNAMIC SPECS}

According to onshore experimental data of a $5 \mathrm{~m}^{2}$ kite with tethers length of $80 \mathrm{~m}$ presented by Behrel et al. [2017], $\varepsilon_{k}$ and $C_{l k}$ are not necessarily constant. Consequently, a linear dependency of $\varepsilon_{k}$ and $C_{l k}$ with the absolute value of the heading rate $\dot{\gamma}$ is proposed as follows:

$$
\varepsilon_{k}=\varepsilon_{0}+\kappa_{\varepsilon}|\dot{\gamma}|, \quad C_{l k}=C_{l 0}+\kappa_{l}|\dot{\gamma}|
$$

Effects of this correction technique are presented in Figure 2 where a comparison of the phase averaging of the experimental data with the modified zero-mass and the classical zero-mass model with constant $\varepsilon_{k}$ and $C_{l k}$ are presented.

The noise of the corrected results are due to the double time differentiation of the experimental trajectory to obtain $|\dot{\gamma}|$. The classical zero-mass model curve with $\varepsilon_{k}=0.217 \mathrm{rad}$ and $C_{l k}=0.855$, in dash-dotted line, underestimates widely the amplitude of the tether tension. The modified zero-mass model, with $\varepsilon_{0}=2.013 \cdot 10^{-1} \mathrm{rad}$, $\kappa_{\varepsilon}=1.878 \cdot 10^{-1}, \quad C_{l 0}=9.856 \cdot 10^{-1}$ and $\kappa_{l}=1.654 \cdot 10^{-1} \mathrm{~s}$, shows a better amplitude agreement compared to the experimental data. The tension obtained with the modified zero-mass remains in the interval $\pm 2 \sigma$ around the experimental curves. However, this correction is questionable since in practice the underestimation of the tension amplitude may be attributed to many other parameters. Nevertheless, such
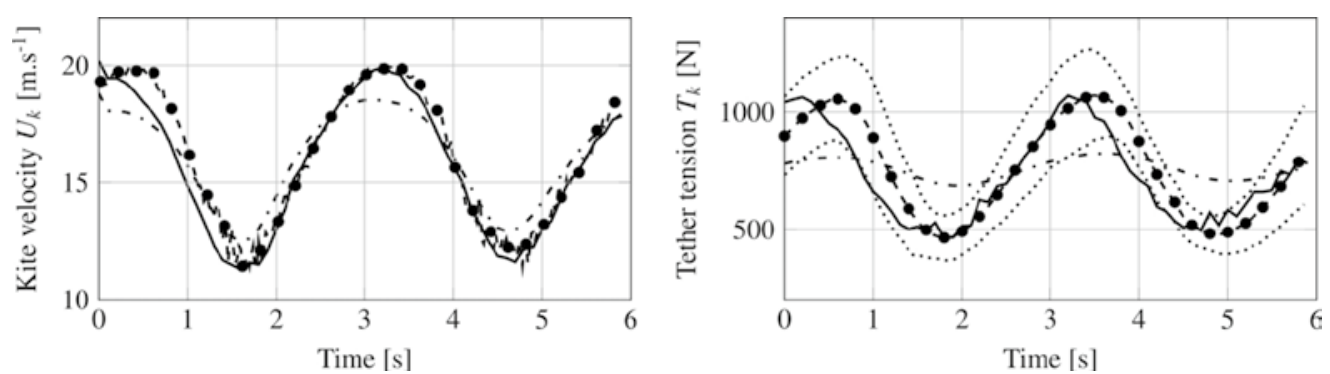

Figure 2 : Evolution along the average trajectory of the kite velocity and of the tether tension at point $A$; - denotes the modified zero-mass model; --- denotes the classical zero-mass model with constant lift to drag angle and lift coefficient; - $\bullet-$ denotes the onshore experimental data obtained by average phasing; $\cdots . .$. double standard deviation $\pm 2 \sigma$ of the experimental data. 
a correction increases the amplitude of the kite excitation, leading to results closer to experimental data, which is conservative for ship motions predictions.

\section{4 COMPARISONS BETWEEN THE STRONGLY COUPLED MODEL AND THE WEAKLY COUPLED MODEL}

A comparison between the presented strongly coupled system and its corresponding weakly coupled system was performed. Free motions of the ship are heave, roll and pitch. The case of study is the full scale DTMB 5512 with a $500 \mathrm{~m}^{2}$ kite at reaching. The mean ship speed is $7.5 \mathrm{~m} \cdot \mathrm{s}^{-1}$ and the reference wind speed is $U_{r e f}=7.5 \mathrm{~m} . \mathrm{s}^{-1}$ at a reference altitude of $10 \mathrm{~m}$ above the sea level. The wind gradient effect is taken into account according to the classical power law [Peterson and Hennessey, 1978]: $U_{t w}=U_{t w}\left(K_{z} / z\right)^{1 / 7}$. The kite follows a Lissajous trajectory such as defined in [Bigi et al., 2017], with constant angular amplitude. Consequently, the shorter the tether length is, the higher the kite excitation frequency is. Only roll motions are presented. Indeed, heave and pitch motions results are not presented since the kite excitation is not critical for these degrees of freedom. The amplitude of the heave and pitch motions are respectively in the magnitude of $0.01 \mathrm{~m}$ and $0.01^{\circ}$.

Figure 3 shows the spectrum of the kite excitation and the ship roll response for a tether length of $380 \mathrm{~m}$. The first harmonic corresponds to the trajectory frequency. The second harmonic is the most important one. With the strong coupling simulation, the second harmonic tends towards the natural roll frequency of the ship at $0.56 \mathrm{rad} . \mathrm{s}^{-1}$.

In figure 4, the ship roll amplitude is plotted for different tether lengths between $250 \mathrm{~m}$ and $1500 \mathrm{~m}$. Three peaks of roll responses can be noticed. They correspond to a tether length leading to the equality of the second, third and fourth harmonic of kite excitation with the natural roll frequency of the ship. Nevertheless, the weak coupling overestimates the amplitude of these peaks. The relative differences of the amplitude of these three peaks are $8.9 \%, 7.9 \%$ and $8.9 \%$. However, the gap between the weak and the strong coupling decreases at the bounds of the frequency range considered. The heave and pitch natural frequencies are around 1 rad.s-1, consequently only the third and fourth harmonics of the kite excitation could be critical to these motions. Nevertheless these harmonics are of low amplitude.

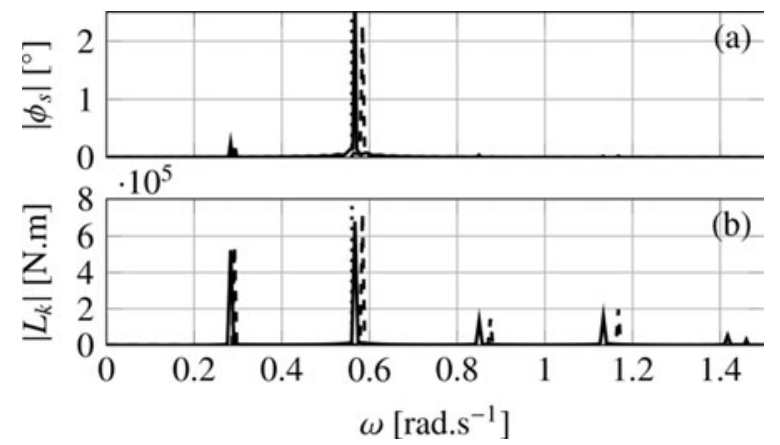

Figure 3: Ship roll motion spectrum (a) and kite heeling moment excitation spectrum (b) for a tether length $L_{t}=380 \mathrm{~m}$

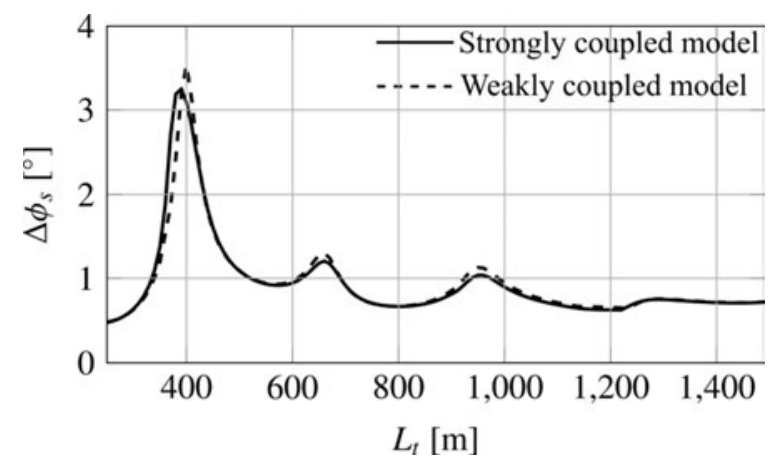

Figure 4: Evolution of the amplitude of the roll motion of the ship with the tether length.

Finally, the coupling between the kite and the ship becomes slightly significant when a harmonic of the kite excitation corresponds to the natural roll frequency of the ship. In that case, a weak coupling is conservative and is a good first approach. According to the two approaches, tether length between $300 \mathrm{~m}$ and $500 \mathrm{~m}$ should be avoided in order to limit the amplitude of the motions. However, it should be noticed that for tether lengths shorter than $300 \mathrm{~m}$, the wind window is small compared to the kite and the control of the kite may become difficult and critical. Consequently, larger trajectory with longer tether $\left(L_{t}>500 \mathrm{~m}\right)$ should be preferred for the presented case of study.

\section{REFERENCES}

Behrel, M., Roncin, K., Leroux, J.-B.B., Montel, F., Nême, A., Jochum, C., \& PArlier, Y. (2017) - Experimental set up for measuring onshore and onboard performances of leading edge inflatable kites - Presentation of onshore results. Fourth International Conference on Innovation in High Performance Sailing Yachts (INNOV'SAIL). Lorient, France.

Bigi, N., Leroux, J. B., Roncin, K., Nême, A., Jochum, C., \& PARLIER, Y. (2017) - Ship towed by kite in waves: a strongly coupled system. Fourth International Conference on Innovation in High Performance Sailing Yachts (INNOV'SAIL).

Cummins, W. (1962) - The impulse response function and ship motions. David Taylor Model Basin Washington DC.

Fossen, T.I. (2005) - A Nonlinear Unified State-Space Model for Ship Maneuvering and Control in a Seaway. . International Journal of Bifurcation and Chaos, 15(9), 2717-2746.

Leloup, R., Roncin, K., Behrel, M., Bles, G., Leroux, J.-B., Jochum, C., \& PARLIER, Y. (2016) - A continuous and analytical modeling for kites as auxiliary propulsion devoted to merchant ships, including fuel saving estimation. Renewable Energy, 86, 483-496.

PÉrez, T., \& Fossen, T.I. (2008) - Time-vs. frequency-domain Identification of parametric radiation force models for marine structures at zero speed. Modeling, Identification and Control, 29(1), 1-19.

Peterson, E.W., \& Hennessey, J. P. (1978) - On the Use of Power Laws for Estimates of Wind Power Potential. Journal of Applied Meteorology.

Salvesen, N., Tuck, E., \& Faltinsen, O. (1970) - Ship motions and sea loads. Trans. SNAME, 78, 250-287. 